\title{
PRODUCTION OF TEMPERATURE UNIFORMITY IN AN ELECTRIC FURNACE
}

\author{
By Arthur W. Gray
}

\section{CONTENTS}

Page

I. Some fundamental principles underlying temperature control.......... $45^{2}$

2. Previous attempts to secure temperature uniformity in electric furnaces... 453

3. A method of reducing the temperature gradient within a long column of

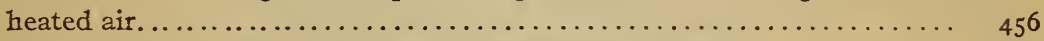

4. Trial application of the double plug to an electric furnace............. $45^{8}$

5. Further development of the electric furnace.................... 460

6. Determination of temperature and temperature distribution........... $46_{3}$

7. Distribution of temperature in the improved electric furnace........... 466

The problems of modern science that demand nicety in the matter of temperature control are steadily becoming more numerous and more important. The requirements are, (I) to produce a sufficiently uniform temperature throughout the region to be used; (2) to maintain this for a sufficient time close enough to the particular temperature desired.

The difficulties of producing a uniform temperature throughout an extended region increase rapidly as the desired temperature departs from that of the room. Stirred liquid baths are generally troublesome at high temperatures. While the advent of the electric furnace marked a considerable improvement over previous methods of heating, nevertheless the temperature distributions within furnaces heretofore described indicate methods of control that are not altogether satisfactory.

It is the purpose of the present paper to set forth a method which has made it possible to heat a region of considerable length to any desired temperature up to about $700^{\circ} \mathrm{C}$ so uniformly that irregularities in the temperature distribution will be less than the effect of heterogeneity in thermoelements of the best quality, and probably less than the uncertainties at present existing in our knowledge of the temperature scale itself. The method has been 
applied to a furnace designed to heat uniformly bars under measurement for thermal expansivity, but the application of it clearly is not limited to problems of this general character. ${ }^{1}$

\section{SOME FUNDAMENTAL PRINCIPLES UNDERLYING TEMPERATURE CONTROL}

If a region in which no heat is generated or absorbed be surrounded by an isothermal envelope maintained constantly at the same temperature, all points within will ultimately come to this temperature. The approach to thermal equilibrium will be hastened by anything which increases the influence of radiation, conduction, or convection within the region. The main difficulty of the problem, then, reduces to that of securing such an isothermal envelope. When the temperature of the surroundings is fairly uniform and constant and is not far removed from the temperature desired, no great trouble is experienced. When such surroundings are not present, the logical procedure is to create them artificially as well as existing conditions will permit.

If the region in question has, by any suitable means, been heated uniformly to the desired temperature $T$, then any procedure which will eliminate heat loss or gain at every point of the surface will maintain $T$ constant and uniform. The time rate $d Q / d t$ at which heat will be conducted away from any portion of the bounding surface in consequence of a normal temperature gradient $-d T / d N$ and a thermal conductivity $k$ in the surrounding substance, will be directly proportional to both $d T / d N$ and $k$. Incasing the region in a poor conductor of heat will reduce the latter, and making the layer thick will reduce the former; but this procedure will not completely eliminate either of these factors. However, $d T / d N$ and, consequently, $d Q / d t$ can be made to vanish by supplying heat around the surface in such a way as to compensate exactly for the loss at every place. But the accurate regulation of such a supply presents difficulties which augment rapidly as $T$ departs from the surrounding temperature, because the increased heat flow involved is subject to greater irregularities of surface distribution and to greater fluctuations with time. Conductivity

\footnotetext{
1 Some results were communicated at the Washington meetings of the American Physical Society in December, $19 \mathrm{I}_{1}$, and in April, rgI3; and the more important features were outlined in a communication to the Washington Academy of Sciences. (A. W. Gray, J. Wash. Acad. Sc., 2, p. 248; rgr2.) Since the publication of this paper the furnace has been improved and more data concerning its performance have been obtained.
} 
parallel to the boundary, or the much more efficient action of a circulating fluid, will promote a uniform distribution of both the losses and the supply. The usual practice of abundant thermal insulation outside the source of heat will reduce variations in the losses, but not in the supply; but the effect that variations in either will produce upon the temperature of the region to be controlled can be materially lessened by the introduction of an insulating layer between the region and the source, since the mere separation of the two will reduce the already small $d T / d N$ and also its rate of change $\frac{d}{d t}\left(\frac{d T}{d N}\right)$ at the surface of the former, while the reduction in $k$ will still further lessen $d Q / d t$ and $d^{2} Q / d t^{2}$. Whatever variations continue to exist near the region can be minimized by applying a small, properly regulated supply of heat around the surface, but best separated from it by an insulating layer, for the reasons just given. Since the addition of heat can usually be regulated more delicately than its removal, it is generally advisable to insure that the temperature of the main source of heat (the outside one) shall never exceed that of the region to be controlled.

\section{PREVIOUS ATTEMPTS TO SECURE TEMPERATURE UNIFORMITY IN ELECTRIC FURNACES}

Previous experimentors have tried to secure uniformity of temperature in an electrically heated air column by using the central portion of a long tube and by crowding the windings near the ends or other places where heat was lost most rapidly. In this way Daniel Berthelot ${ }^{2}$ secured uniformity within $2^{\circ}$ over the central $22 \mathrm{~cm}$ of a tube $85 \mathrm{~cm}$ long heated to $917^{\circ}$. Jaquerod and Perrot $^{3}$ in a well-insulated furnace without crowded windings heated a gas thermometer bulb $8 \mathrm{~cm}$ long with variations of less than $2^{\circ}$ at $1066^{\circ}$. Waidner and Burgess ${ }^{4}$ constructed a black body in which compensation for heat losses through the ends was secured in great measure by the use of a second independent heating coil surrounding the first and projecting $8 \mathrm{~cm}$ beyond each end. The winding of the secondary coil was very close

- about the ends and very open about the center. At $1245^{\circ}$ this arrangement gave such remarkably uniform temperature that

${ }^{2}$ D. Berthelot: Ann. Phys. et Chim., 26, p. Irg; xgo2.

3 A. Jaquerod and F. I. Perrot: Archives des Sciences Phys. et Nat., 20, pp. 45, 57; 1905.

4 C. W. Waidner and G. K. Burgess: This Bulletin 3, p. 165; 190\%. 
there was no variation of more than one or two tenths of a degree over a length of $12 \mathrm{~cm}$. However, the method of varying the distribution of heat supply to compensate for lack of uniformity in the distribution of heat losses suffers from two serious defects: (I) It is a method of cut and try; (2) the proper arrangement to secure uniformity at one particular temperature does not give uniformity at any other temperature, necessitating a repetition of the cut-and-try process for every temperature desired. This is strikingly illustrated by one of the compensated black bodies used by Waidner and Burgess. While the temperature uniformity was practically perfect for $\mathrm{I} 2 \mathrm{~cm}$ in front of the radiating diaphragm at $1245^{\circ}$, drops of $8^{\circ}, 10^{\circ}$, and $\mathrm{II}^{\circ}$ took place within the second $4 \mathrm{~cm}$ of this same region when the diaphragm was at $62 \mathrm{I}^{\circ}, \mathrm{IO}_{4} \mathrm{I}^{\circ}$, and $\mathrm{I} 308^{\circ}$, respectively. This is shown graphically in Fig. $\mathrm{I}$, where the distribution obtained by Jaquerod and Perrot is also represented.

The remarkable temperature uniformity exhibited by the black body used by Waidner and Burgess, is, however, an isolated example. It was obtained in one particular series of observations, at one particular temperature, and extended only for a short distance. The best results so far recorded in the way of heating a fair length at widely differing temperatures appear to be those obtained by Day and Sosman; and because they are the best that the writer has succeeded in finding, they will be referred to freely for purposes of comparison. The difficulties that Day and Sosman encountered in their attempts to heat uniformly a platinum-iridium bar $25 \mathrm{~cm}$ long, the linear expansivity of which they were determining, is best stated in their own words: ${ }^{5}$

The problem of accomplishing this result gave us considerable anxiety. As has been stated above, the scheme of making optical measurements directly upon the bar without multiplying devices of any kind necessarily involves an opening in the furnace coil opposite each end of the bar, and a consequent cooling of that portion of the bar which is opposite the opening. ${ }^{6}$ The amount of this cooling, which is greatest

\footnotetext{
${ }^{5}$ In a paper by A. I. Day and J. K. Clement: Am. J. Science, 26, p. 425 ; r9o8.

6 These openings must be of sufficient size for good vision through them with a microscope. If too narrow, they are almost sure to produce such errors as arise from asymmetry of the light entering the objective and from inability to focus accurately. By using the suspended-wire method of measuring elongations (A. W. Gray, J. Wash. Acad. Sc., 2, p. 248; 1912. To be described in greater detail in an early number of this bulletin), the necessary openings may be reduced to narrow slits barely large enough to secure free motion to the wires, and these slits may be extended to the outside of the furnace by long tubes of the same cross section. In this way the disturbance of temperature caused by these openings may be rendered negligible, and at the same time the improvement in the optical conditions is considerable.
} 
at the highest temperatures, reached a value of about 4 per cent in the first furnace coil (furnace I) which we wound. * * * Accordingly, another furnace coil (furnace II) was wound with the turns closer together near the openings. This changed the temperature gradient considerably without materially improving it, after which a third coil was prepared with still closer windings, which proved to be considerably overcompensated and was rejected. In all, we made five separate trials of this kind, in the last two of which (furnaces III and IV) a thick-walled iron tube was substituted

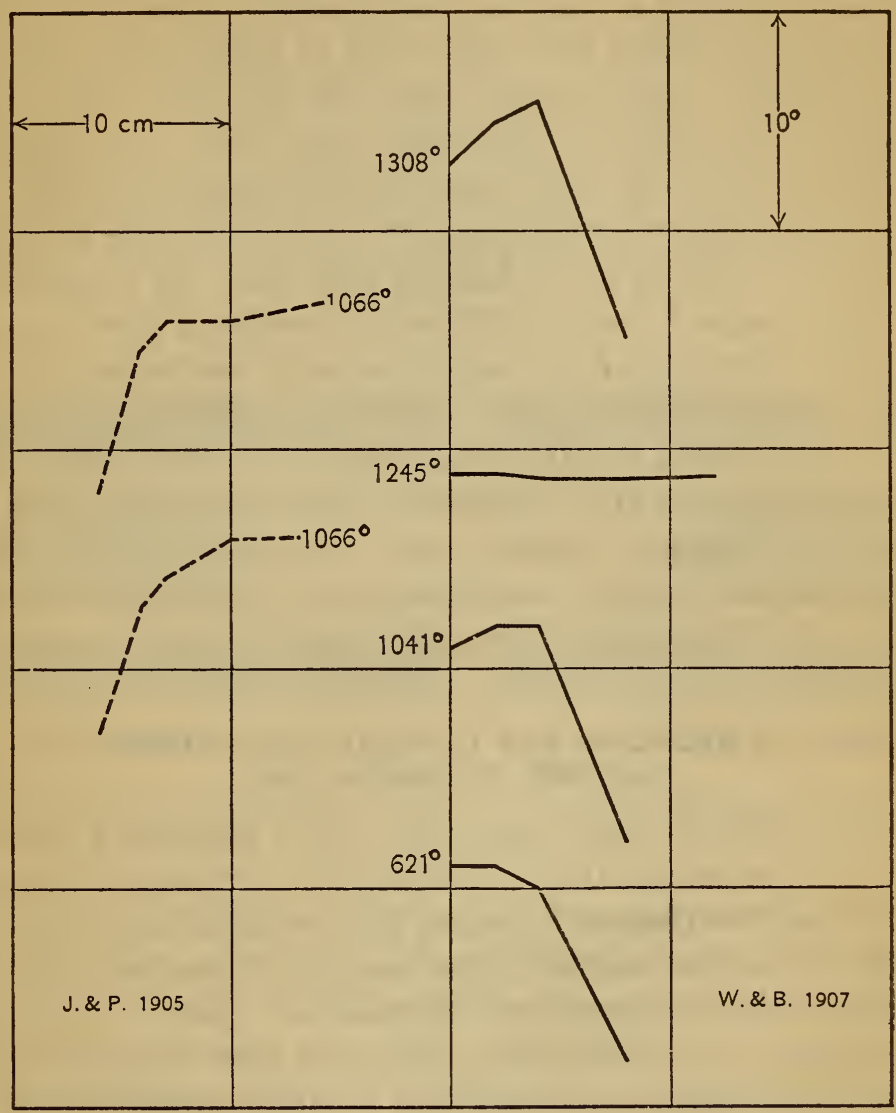

Fig. 1.-Temperature distribution in the gas-thermometer furnace of Jaquerod and Perrot, and in a black body of Waidner and Burgess

for the porcelain furnace tube in the hope of gaining increased uniformity of temperature through the increased heat conductivity of the tube itself. This arrangement succeeded better, but we found it impossible so to arrange a winding that the temperature opposite the openings was uniform with that at the middle of the tube for all temperatures between 0 and $1000^{\circ}$. A winding which gave good results at the lower temperatures gave insufficient compensation at the higher ones. The obvious possibility of reaching a uniform distribution by subdividing the coil into sections in each 
of which the current could be independently varied ${ }^{7}$ was not tried on account of the cumbersome manipulation required, and in part also because the results which we obtained with considerable differences in the gradient appeared to agree very well among themselves.

Day and Sosman state that the deviations within the central $24 \mathrm{~cm}$ of their furnaces III and IV amounted to $5^{\circ}$ at $300^{\circ}$, increasing steadily to about $20^{\circ}$ at $700^{\circ}$ and reaching about $50^{\circ}$ at $1000^{\circ}$. While the thick-walled iron tube used in these latter trials produced markedly better results than the porcelain tube used in the earlier ones, still it is quite clear that even the conductivity of the iron was very far from adequate to secure uniformity, especially at temperatures much removed from the one at which a particular distribution of the heating coils gave the best results.

In a later paper $^{8}$ Day and Sosman describe a new furnace 70 $\mathrm{cm}$ long for determining the expansion of a $50-\mathrm{cm}$ bar; but they give no data concerning the temperature distribution they secured. They merely remark that, since it was impossible to wind the furnace so as to give a perfectly uniform temperature along the bar, the furnace winding and consequent distribution of temperature were varied considerably for each run, in the hope of eliminating uncertainty from this cause in the average of all observations.

\section{A METHOD OF REDUCING THE TEMPERATURE GRADIENT IN A LONG COLUMN OF HEATED AIR}

In order to secure data that would aid in improving the design of electric furnaces suitable for expansivity determinations, especially in the direction of reducing the longitudinal temperature gradient, the writer studied experimentally the effect of various factors upon the temperature distribution within a long cylindrical air bath. A return-flow, oil-heated tube was used for the purpose of obtaining uniform lateral heating, so as to avoid confusing the observations by the effect of such irregularities as would be almost sure to exist in an electrically heated helix, no matter how carefully wound.

It is unnecessary here to enter into a detailed description of the many experiments made with this tube. ${ }^{\circ}$ For our present

\footnotetext{
7 This method, though resembling to a certain extent that to be described in the present paper, differs radically from it not only in constructional details but also in the fundamental principles involved.

8 A. I. Day and R. B. Sosman: Am. J. Science, 29, p. Iri; rgro.

9 The writer is indebted to Mr. M. D. Hersey for assistance in carrying out this preliminary work.
} 
purpose it will suffice to direct attention to a simple device in which the principles enunciated in the preceding sections have been successfully employed, viz, a plug formed of two thick blocks of a good heat conductor separated by a considerable layer of a poor conductor. For convenience the conducting blocks are united by a thin metal shell containing the insulator. Fig. 2 represents one in each end of the tube, the circumference of which is heated by a fluid circulating spirally around it and returning to the inlet end by linear flow through an outer concentric passage. In such a return-flow tube, the ends of which were plugged for Io $\mathrm{cm}$ essentially as indicated, though not quite so well, an air column $4 \mathrm{~cm}$ in diameter and more than a meter long has been
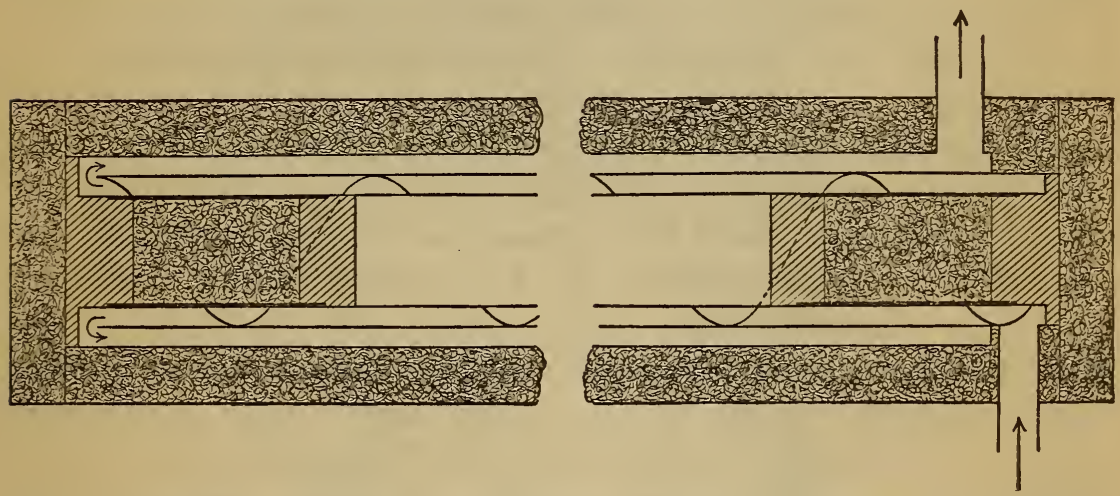

Fig. 2.-Oil-heated return-flow tube, showing double plugs for reducing the temperature gradient

repeatedly heated by circulating oil to over $100^{\circ} \mathrm{C}$ so uniformly throughout its entire length that right against the plugs the temperature was only a few hundredths of a degree lower than in the center, while several centimeters farther inward the drop was only a few thousandths. Yet with the ends closed by equally long plugs of such heat insulators as cotton wool and cork there was a marked lowering of the temperature in the immediate vicinity within, even when the interior was only slightly warmer than the room; and in many of the experiments made this drop was apparent for a long distance within the tube. If the inside tube (of brass, I mm thick) were extended $4 \mathrm{~cm}$ beyond the heating jacket, relatively enormous end effects were produced in the air column, especially if the projections were not well pro- 
tected by lagging. But unhindered radiation and conduction through the sides of the tube to the surrounding air was found to disturb the distribution of temperature within only slightly. In nearly all cases where the tube was not surrounded by an insulating jacket there was evidence of a small progressive drop in temperature in the direction away from the inlet and exit end. Doubtless this could have been made imperceptible by substituting a poorly conducting tube for the thin brass one separating the oppositely directed currents of heating fluid.

\section{TRIAL APPLICATION OF THE DOUBLE PLUG TO AN ELECTRIC FURNACE}

The double plug with small temperature gradient across an insulating layer described in the preceding section indicated a way of reducing such difficulties as were previously enumerated. Accordingly, an electrically heated furnace was constructed for determining the expansivity of bars, the elongations being measured by the suspended-wire method. ${ }^{10}$ Fig. 3 represents the essential features. Since this furnace was designed primarily for convenience of manipulation and for securing merely moderate uniformity of temperature, only a partial use was made of the principles enunciated in section $\mathrm{I}$. The furnace tube, of iron fairly uniformly wound for its entire length with constantan ribbon, had its central portion completely filled with an iron block pierced by two longitudinal cavities, of square cross section, symmetrically situated above and below the geometrical axis of the tube. The lower cavity was almost completely filled by the bar to be measured, while the upper one contained a similar dummy bar, the temperature of which was determined by a thermoelement placed within a hole following the axis of the bar. While the conductivity of the large metal masses probably contributed considerably toward the production of temperature uniformity within this furnace, and while the smallness of the passages required for the suspended wires certainly prevented much disturbance, a very important feature of the whole construction was undoubtedly the type of plug used for closing the ends. This was essentially the same as the simple one described above, with the addition of an 
independent electrical heating coil wound in a groove within the outside conducting block. This coil made it easy to maintain the end at a temperature almost the same as that of the interior, thus reducing the longitudinal temperature gradient and thereby the outward conduction of heat. Suitably arranged differential thermoelements in the plugs, together with a convenient grouping of rheostats, made the temperature control an easy matter.

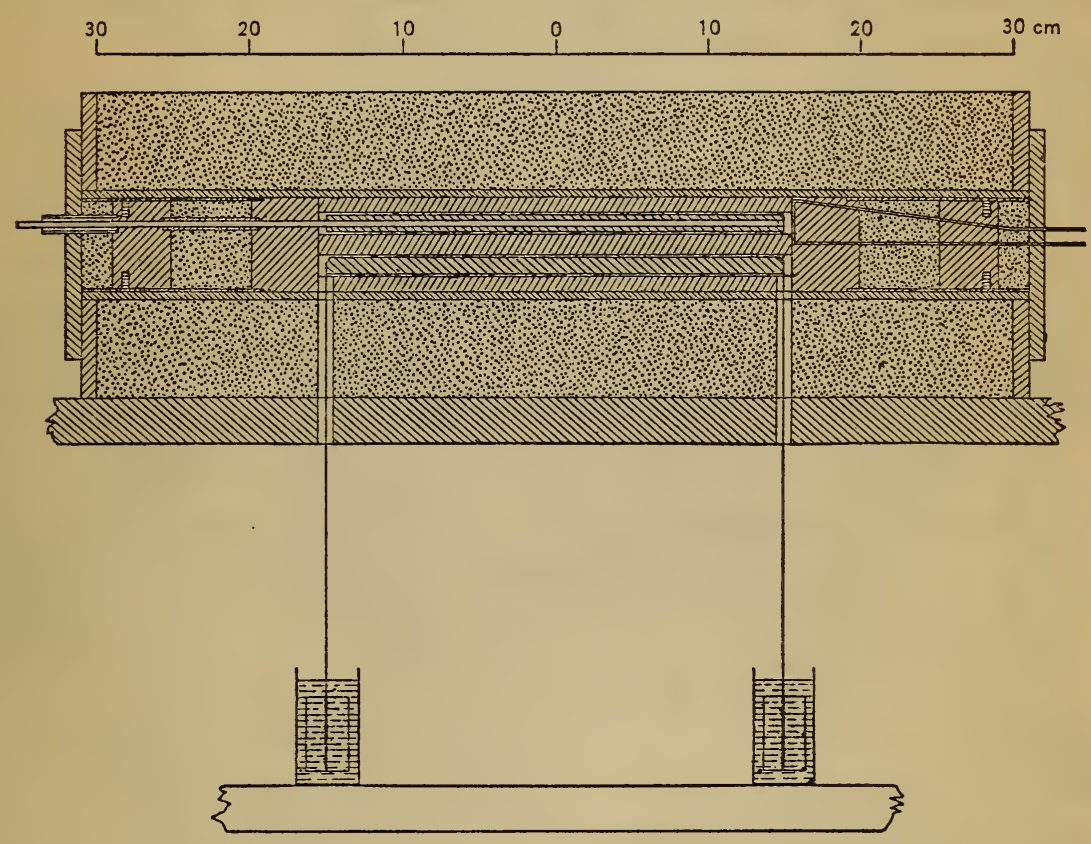

Fig. 3.-First electrically-heated furnace for expansion measurements by the method of suspended wires, showing double plugs with outside blocks independently heated

The furnace was built to accommodate bars $30 \mathrm{~cm}$ long. Examination of the temperature distribution throughout this length for various temperatures up to $684^{\circ} \mathrm{C}$. showed that, if the outside end of the plugs was within $10^{\circ}$ of the interior, no variation exceeding a few tenths of a degree occurred in the right-hand $15 \mathrm{~cm}$ except at the highest temperature to which the furnace was forced, when the extreme deviation was found to be $4^{\circ}$. Since the consiantan ribbon burned out in the vicinity of the hottest place the next day, considerably before this temperature was again reached, 
it seems likely that this deviation was due to excessive local heating. The left-hand half of the bar did not, however, seem to be so uniformly heated as the right and was apparently consistently warmer, the maximum rise of $2^{\circ}$ occurring in the second $5 \mathrm{~cm}$ from the left end. At the time this asymmetry was attributed to irregularity in either the heating coil or the insulation. Later, however, an investigation of the thermoelement used in exploring the temperature distribution disclosed sufficient heterogeneity to account for the apparent irregularity in both magnitude and location.

It is to be noted that, contrary to general experience with the method of crowded windings for reducing the gradient within electric furnaces, the distribution at any one temperature observed in the furnace closed by double plugs did not differ essentially from that observed at any other temperature. Even making the outer ends of the plugs considerably colder than the interior affected the temperature within but little.

\section{FURTHER DEVELOPMENT OF THE ELECTRIC FURNACE}

Since the performance of the trial electric furnace made apparent the efficacy of the end-heated double plug, conducting transversely while insulating longitudinally, as a means for controlling the longitudinal temperature gradient, the necessity for rewinding the burned-out heater was made the occasion for remodeling into a more permanent form. Certain changes in design were made to secure a fuller application of the principles discussed in section $\mathrm{I}$. Other changes facilitated manipulation and investigation. Fig. 4 is a photograph of the new furnace and of the comparator as arranged for expansion measurements. Fig. 5 shows in section the more important features. For the sake of clearness minor structural details, as well as the bars and thermoelements, have been omitted.

The iron tube of the trial furnace, together with its contents, is retained without essential alteration. The principal change consists in removing the heating coil from the tube $\mathrm{A}$, upon which it had formerly been wound, and substituting two independent concentric heaters (wound on the iron pipes B and C) to supply heat uniformly for the entire length of the interior. In the experi- 


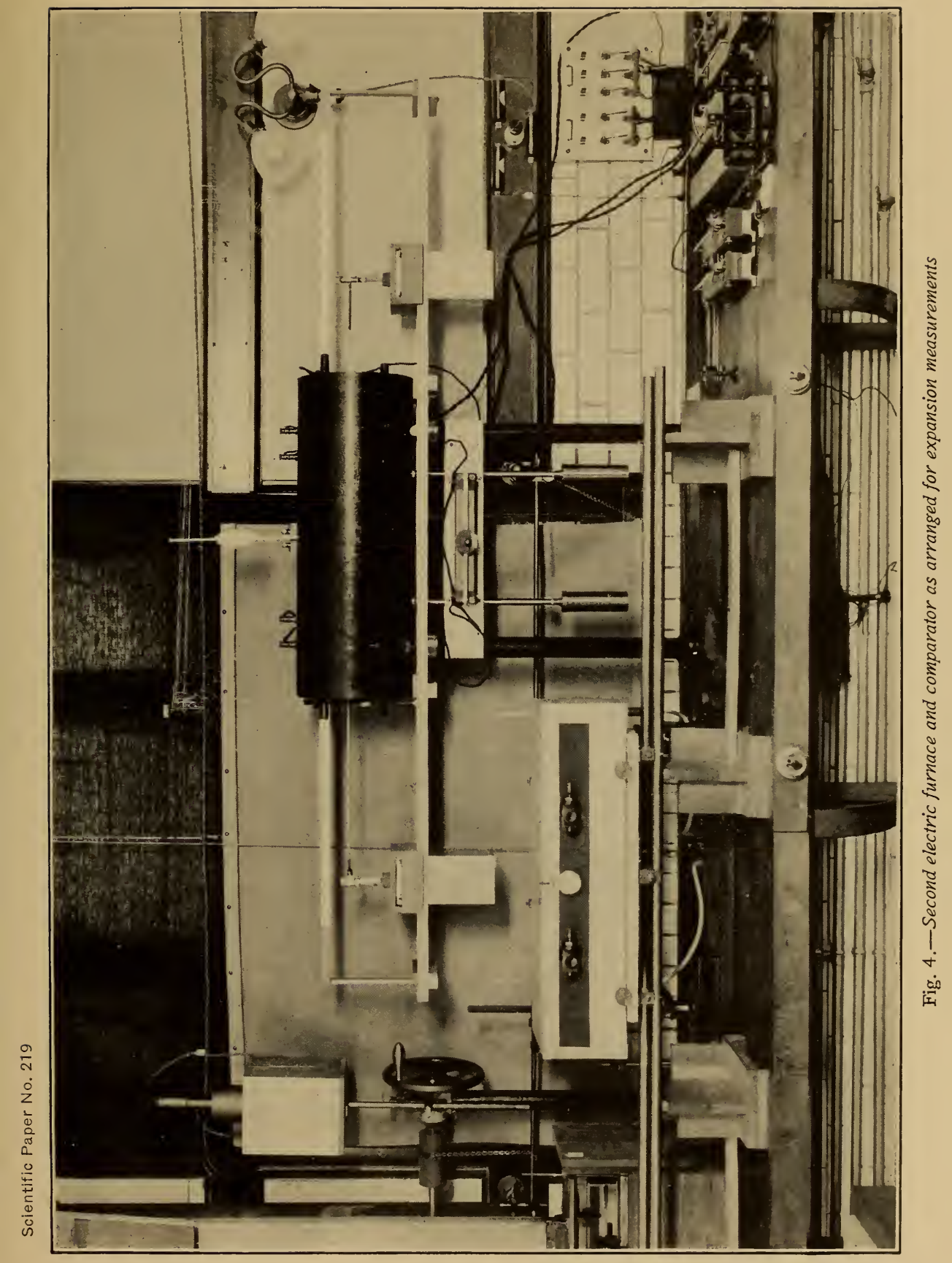




Scientific Paper No. 219

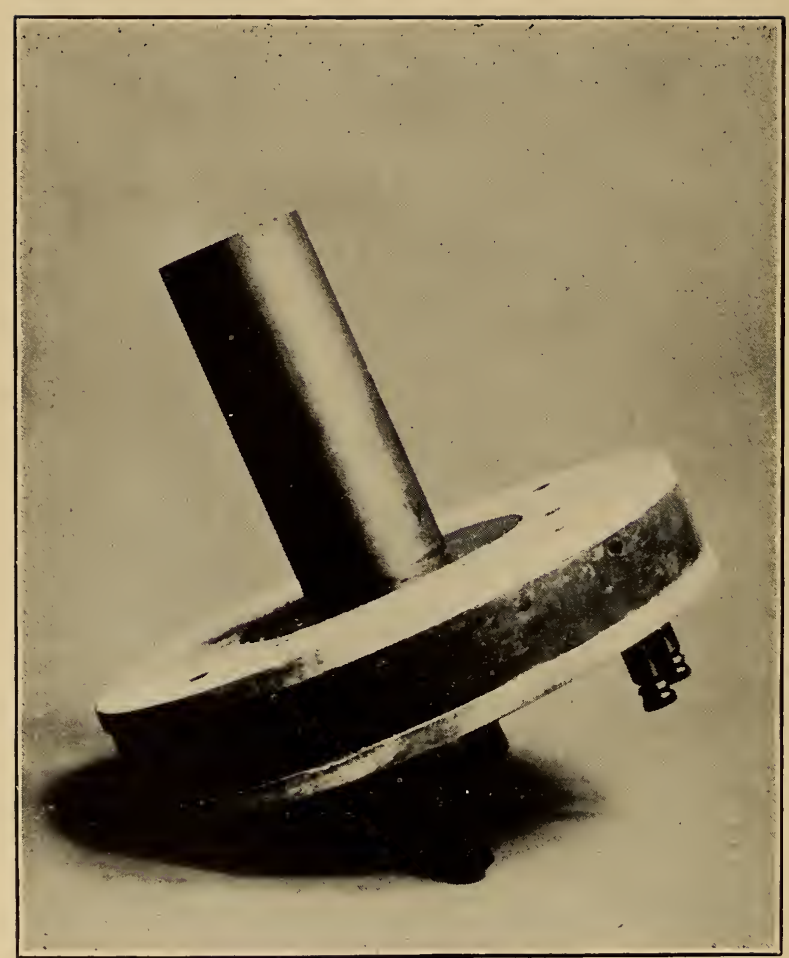

Fig. 6.-A double plug with flat end-heating coil 
ments so far made, air has formed the insulation filling the annular spaces between $A$ and $B$ and between $B$ and $C$, except for some layers of mica and of asbestos cloth, in all about $4 \mathrm{~mm}$ thick, wrapped tightly around the heating ribbon on $\mathrm{B}$. $\mathrm{C}$ is covered in the same way, and then the surrounding space to the pipe $D$, which forms the outer shell of the whole furnace, is filled with asbestos-magnesia compound. Both of the end plugs are pierced by tubular openings for inserting thermoelements within the dummy bar. Large insulating heads, each composed of two disks $\left(\mathrm{E}, \mathrm{F}\right.$ and $\mathrm{E}^{\prime}, \mathrm{F}^{\prime}$ ) of $\mathrm{I} \mathrm{cm}$ asbestos building lumber separated by $3 \mathrm{~cm}$ of asbestos-magnesia compound, fill the whole cross section at the ends of the casing $\mathrm{D}$ and reduce heat losses. These heads are rigidly attached to the double plugs, and carry binding posts leading to the heating coils, as well as handles to facilitate insertion

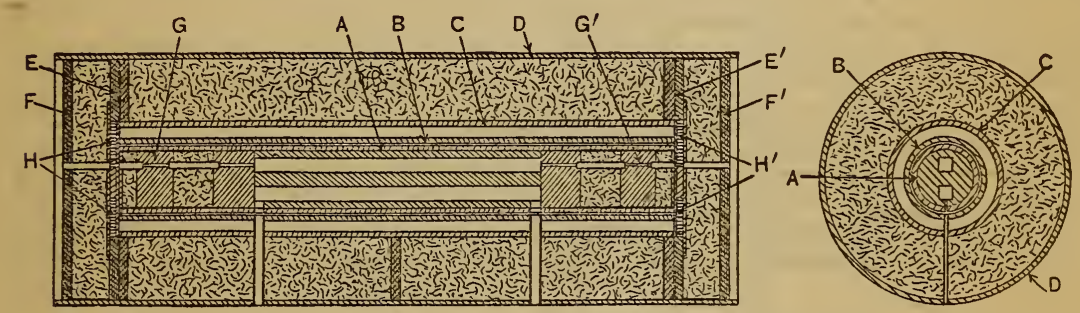

Fig. 5.-Section of second electric furnace, showing more or less diagramatically the more important features

and removal. In most of the experiments with this furnace heat was supplied to the plugs by means of the coils described in section 4 and illustrated in Fig. 3. Recently, for reasons that will appear later, the coils filling the grooves in the blocks $\mathrm{G}$ and $\mathrm{G}^{\prime}$ were cut out of action, and two new coils $\mathrm{H}$ and $\mathrm{H}^{\prime}$ were substituted. These are flat coils of the same diameter as the tube $C$, against the ends of which they bear. Space for them was provided by removing the central portions of the disks $\mathrm{E}$ and $\mathrm{E}^{\prime}$. One of the remodeled plugs is illustrated by the photograph Fig. 6.

The heaters that cover the pipes $\mathrm{B}$ and $\mathrm{C}$ are of nichrome ribbon wound longitudinally instead of helically. The construction is indicated in Fig. 7. A flat mat is made of the resistor ribbon and strips of micabeston ${ }^{11}$ woven together in basket fashion. This

\footnotetext{
11 An insulating preparation of mica flakes and a resinous cement pressed into large, thin, flexible sheets.
} 
is wrapped about the heater tube (previously covered with a layer of micabeston), and the opposing ends of each insulating strip are lapped for a short distance and tucked under alternate lengths of the ribbon. Then follows another layer of micabeston, and, finally, a wrapping of asbestos cloth. As each layer is applied it is drawn down firmly by a tight helical bandage of cotton tape, which is removed as soon as the layer has been cemented in place by warming and then cooling the tube. The final wrapping of asbestos cloth is secured by a bandage of nichrome ribbon. The lengths of ribbon bounding each edge of the mat and the two on either side of the middle are left long enough at one end to serve as electrical terminals. When the heater is wound, these terminals come out at opposite ends of a diameter at one extremity

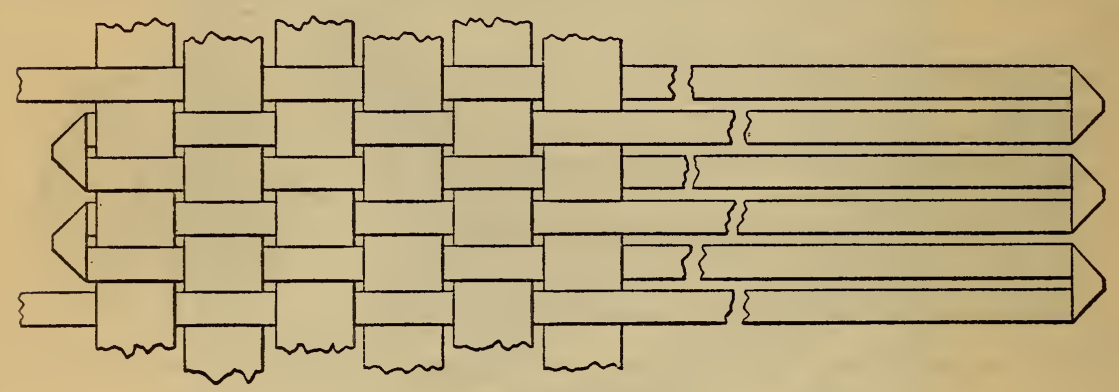

Fig. 7.-Diagram of furnace winding

of the tube, and they connect the two halves of the winding in parallel. Each pair of large binding posts seen on top of the furnace in Fig. 4 leads to one of the concentric heaters. After a heater is wound, current is passed through it until it is thoroughly baked to remove all the resinous cement.

This method of winding possesses the following advantages: (I) Any irregularities in the resistance of the heating ribbon are distributed in such a way as to produce a minimum effect upon the longitudinal distribution of temperature; (2) the winding is non-inductive; (3) the maximum difference in electrical potential that can occur between adjacent portions of the winding is limited to the drop in a length of ribbon twice as long as the furnace. This makes the danger of arcing by accidental contact considerably less than in the ordinary form of noninductive winding; 
(4) if adjacent windings should accidentally touch, only a short length of ribbon could be short circuited; (5) spaces for the side openings down which the length-defining wires are suspended can be provided without affecting the heat supplied per unit length of the furnace tubes; (6) the location of the terminals combines both convenience and safety.

A furnace of the type here described requires considerable time to attain thermal equilibrium. The lag, however, causes no great inconvenience, because in any precise expansion determinations sufficient time should be allowed for the specimen to reach mechanical equilibrium; that is to say, for all unbalanced internal stresses to disappear. The gain in temperature uniformity and constancy more than counterbalances any time lost from avoidable lag. Nevertheless, it seems likely that a furnace amply sufficient for most purposes could be made with considerably less lag. In this connection it might be mentioned that the principal use of the inner concentric heater is to hasten the attainment of approximate thermal equilibrium. Experience has shown that when the proper adjustment has been secured, the steadying action of the insulation within the outer heater is sufficient to wipe out fluctuations in both losses and supply of heat. ${ }^{12}$

\section{DETERMINATION OF TEMPERATURE AND TEMPERATURE DISTRIBUTION}

It was convenient and sufficiently accurate to determine all temperatures within the furnace described in section 5 by means of $P t-P t R h$ thermoelements. These were all made from the same spools of the highest purity Heraeus wire and did not show sufficient heterogeneity to cause inconvenience. One element kept as a reference standard was calibrated by the heat division of this Bureau at the freezing points of copper, silver, antimony, and zinc, and at the boiling points of naphthalene and water. Two others, conveniently mounted within sealed protective casings, were used in the actual determinations, one entering each

\footnotetext{
12 The use of two concentric heaters bears some resemblance to the cascade furnace described by Harker (Proc. Roy. Soc., A, 76, p. 237; 1905) for reaching a temperature of about $2000^{\circ}$ in a heater tube made of the same material as Nernst lamp glowers. To avoid the necessity of having contacts on this tube capable of carrying relatively large currents, and the consequent severe stress on the parts, it was surrounded by a coil of nickel wire heated by an independent circuit to about $1000^{\circ}$, and insulated from the inner tube by a layer of zirconia. No precautions seem to have been taken to secure uniformity of temperature within. $46692^{\circ}-14-2$
} 
end of the furnace. The arrangement and the temperature control of the furnace were such as to afford favorable conditions for intercomparison.

A photograph of a protected thermoelement is shown in Fig. 8. The furnace end is encased in a horizontal glazed porcelain tube $4 \mathrm{~mm}$ external diameter and $500 \mathrm{~mm}$ long, closed at the junction end. Within, the wires are separated in the usual way by an unglazed porcelain capillary. The junctions with the copper leads are at the bottom of a vertical glass tube, joined to the porcelain tube by a tee of brass and thin copper tubing, which permits a slight amount of bending. The copper leads reach the outside through a second glass tube within the first. Reserve platinum and platinum-rhodium, to allow for the occasional removal of contaminated ends near the furnace junction, or for lengthening the elements is carried in the form of an open helix coiled around the inner glass tube and bound down with wrappings of thin silk, the cold junctions being located near the bottom, but on the outside of the inner tube, so as to be close to the outer one, which was drawn down thin in this region. All wires and wrappings within the glass tube are thoroughly imbedded in melted paraffin. This mounting furnishes a protection against furnace vapors and electrical leakage along moisture films, and has been found much more convenient than the loose wires formerly used. In Fig. 4 the thermoelement just described appears in position, extending into the right-hand end of the furnace. Another, mounted in much the same fashion, appears at the left. The temporary containers for the ice bottles, which are small cylindrical Dewar flasks surrounded by cotton wool, can be seen hanging from wooden slides that rest upon the long steel track. The millimeter scales above the track indicate the positions of the junctions within the furnace.

A thermoelement with its cold-junction temperature given by a mercurial thermometer extends through the furnace casing and rests against the outer cylindrical heater. A differential element, connected to the binding posts on top of the furnace, indicates difference in temperature between the outer and the inner heater. Another in the left plug gives the difference between the axis and the circumference of the inner end. Stili another, added since 
Scientific Paper No. 219

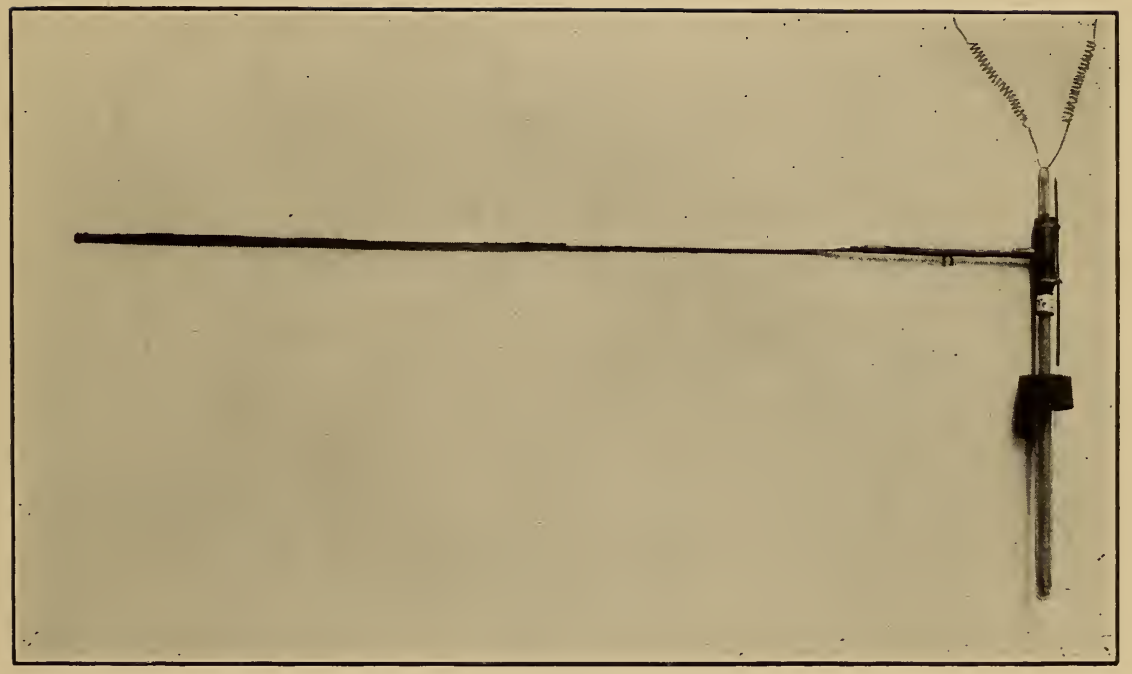

Fig. 8. $-A$ protected thermoelement 



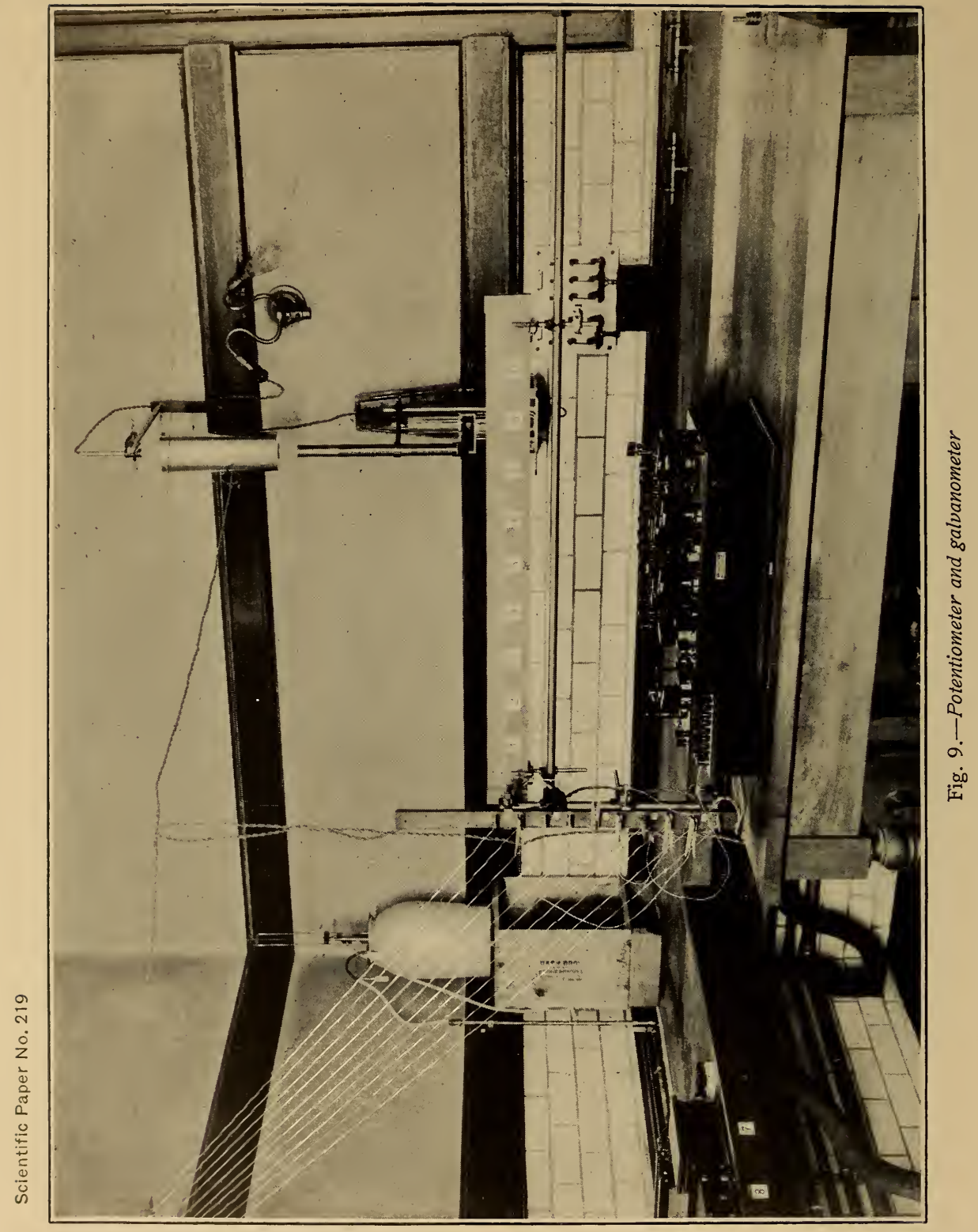


the photograph was made, indicates the difference between the end-heating coils $\mathrm{H}$ and $\mathrm{H}^{\prime}$, Fig. 5 .

The electromotive forces are measured by a five-dial Diesselhorst potentiometer ${ }^{13}$ made by Otto Wolff and calibrated by the electrical division of this Bureau. The galvanometer, of the Jaeger low-resistance type ${ }^{14}$ made by Siemens and Halske, was sufficiently sensitive when critically damped to give a deflection of about $2.5 \mathrm{~mm}$ per microvolt on a scale I meter distant. All galvanometer wires, as well as the potentiometer and storage battery, were insulated from metal equipotential shields connected to earth through the laboratory water pipes. No irregularities have been noticed even on very moist days.

The general arrangement of the galvanometer illumination is shown in Fig. 9. It is similar in principle to some of the devices on the market, but surpasses them in brilliancy of illumination and sharpness of image. The source of light is a General Electric Co.'s concentrated filament, tungsten projection lamp, which is surrounded by a nickel-plated brass tube open at the top and closed at the bottom except for a 4 -cm central hole. The light coming through this opening traverses a vertical telescoping tube, at the bottom of which is a right-angled total reflecting prism for directing it on the galvanometer mirror, whence it is reflected to a Hartmann and Braun lightly frosted glass millimeter scale. At the top of the telescoping tube is an ordinary plano-convex lens, which serves as a condenser and forms an image of the lamp filament on the galvanometer mirror. Just below the condenser is a metal screen with a rectangular opening across which the index extends. This is formed of a piece of wire one-thirtieth $\mathrm{mm}$ in diameter stretched between two short pieces of larger wire, which have been filed to pointed half cylinders so as to obtain sharply defined edges. An achromatic lens just above the reflecting prism forms on the glass scale an enlarged image of the opening and index wires. The images of the larger, pointed wires stand out so clearly on the brilliantly illuminated field (about $\mathrm{I} 7$ by $50 \mathrm{~mm}$ ) that their position can be read within a few millimeters by a person eight or ten meters distant even in a well-lighted room, while the image of

${ }^{13}$ H. Diesselhorst: Zs. f. Instrk., 28, p. I and p. $3^{8 ;}$ rgo8.

11 W. Jaeger: Zs. f. Instrk., 28, p. 206; $x 908$. 
the fine wire permits estimation to a tenth of a millimeter when the observer is close to the scale.

All observations of temperature within the furnace involved the use of both the thermoelements entering it through the ends. The junction of the right-hand element was placed at the center of the dummy bar, with the junction of the left about $2 \mathrm{~mm}$ away, which was as close as the porcelain protecting tubes would permit the junctions to approach each other. The emf of the right element alone was read; also that of both connected in opposition. When making an observation both the emf to be measured and the potentiometer current were reversed and returned to their original directions by means of the oil immersed commutator that accompanies the potentiometer.

To explore the distribution of temperature within the furnace, one thermoelement was located so that the tip of its porcelain protecting tube could be just touched by that of the other when inserted as far as possible. The two elements were connected in opposition. The warm junction of the second was slowly moved through the furnace by sliding the container of the ice junction along its track while galvanometer deflections were noted for various positions. Check readings were taken at several points passed in opposite directions. In the same way the other end of the furnace was explored with the second element fixed while the first was moved. The paths traversed by both junctions overlapped for the central $20 \mathrm{~cm}$ of the furnace. This procedure also yielded comparisons of the thermoelements with three different depths of immersion for each. One millimeter change in deflection indicated a change in temperature of between $0.058^{\circ}$ and $0.086^{\circ}$, depending on the temperature. The sensitivity exceeded the reliability attainable with thermoelements of even the best quality.

\section{DISTRIBUTION OF TEMPERATURE IN THE IMPROVED ELECTRIC FURNACE}

The distribution of temperature was first investigated when the end heating was supplied through the coils in the blocks $G$ and $\mathrm{G}^{\prime}$ (see section 5 and Fig. 5), and before the central portions of the asbestos lumber disks $\mathrm{E}$ and $\mathrm{E}^{\prime}$ had been cut out to make room for the flat coils $\mathrm{H}$ and $\mathrm{H}^{\prime}$. All of the numerous curves obtained 
showed the characteristics of the two reproduced in Fig. Io. The circle on each curve indicates the middle of the furnace. The points $30 \mathrm{~cm}$ on either side were $\mathrm{I} \mathrm{cm}$ within the extremities of the furnace tubes, which were $62 \mathrm{~cm}$ long, the length of the casing being $74 \mathrm{~cm}$. The most striking features of the temperature distribution are the steep gradient beyond the heated blocks and the drop of several degrees just within them. This drop was

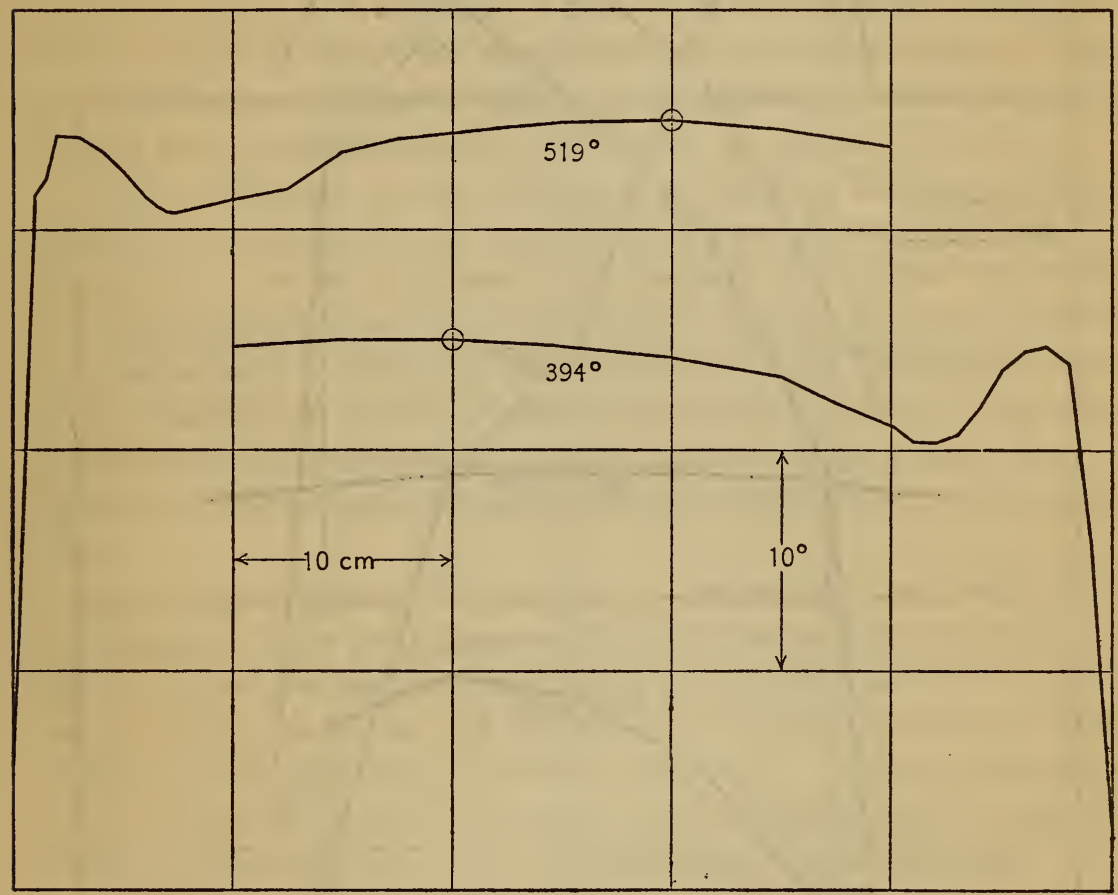

Fig. 10.-Characteristic distributions of temperature in the seccond electric furnace before installing the flat end-heating coils. The small circles indicate the center of the furnace

evidently due to heat losses at the ends caused by radiation or air currents, or both combined, through the annular spaces between the concentric tubes. As will be seen presently, it disappeared completely after installing the coils $\mathrm{H}$ and $\mathrm{H}^{\prime}$ and at the same time closing the ends of the annular spaces with I or $2 \mathrm{~cm}$ of asbestos.

However, in spite of the internal drop, fair uniformity throughout the central $30 \mathrm{~cm}$ for which the furnace was designed could be 
easily obtained by merely raising somewhat the temperature at the ends. Fig. I I presents two examples to show that good per-

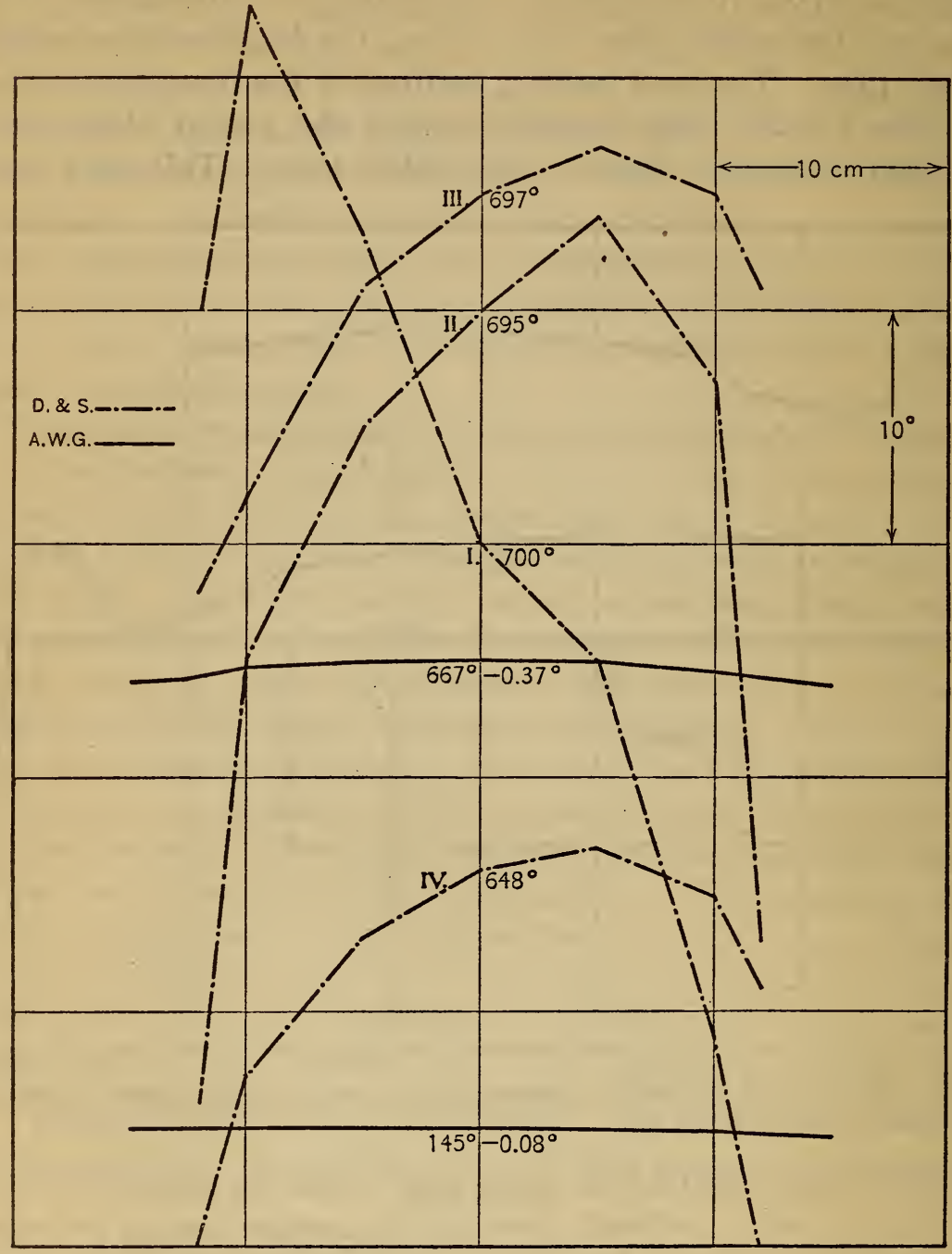

Fig. 11.-Distributions of temperature throughout the central $30 \mathrm{~cm}$ of the furnace shown in Figs. 4 and 5 obtained at $145^{\circ} \mathrm{C}$. and $667^{\circ} \mathrm{C}$. under conditions shown in Fig. 10 . For comparison, temperature distributions obtained by Day and Sosman throughout the central 24 $\mathrm{cm}$ of four different furnaces are plotted on the same scale

formance is not limited to some particular temperature, as we have seen to be the case with furnaces in which adjustment of the 
distribution is attempted by the ordinary cut-and-try method of crowding the windings near the ends. At $667^{\circ}$ the mean temperature throughout the full $30 \mathrm{~cm}$ was $0.37^{\circ}$ lower than the temperature at the center, with a maximum drop of $\mathrm{I}^{\circ}$ at the extreme ends of the interval; at $x 45^{\circ}$ the mean temperature over the same region was $0.08^{\circ}$ lower than at the center, with a maximum drop of $0.25^{\circ}$ at the extreme ends. For purposes of comparison with the best previous work (see section 2) the distributions recorded by Day and Sosman in four of their furnaces at temperatures nearest to $667^{\circ}$ are reproduced in the same figure. These are plotted on the same scales as the writer's curves, for both length and temperature, but cover only 24 instead of $30 \mathrm{~cm}$.

As an indication of the constancy attainable, it might be mentioned that during the 20 minutes that passed while the observations at $667^{\circ}$ were being made the temperature at the center rose $0.067^{\circ}$, or at the rate of $0.2^{\circ}$ per hour. During this period no attention whatever was paid to regulation of the heating currents. From the way in which the furnace always behaved it was clear that even better control as regards both constancy and distribution could have been obtained merely by more careful adjustment.

Some experiments were made to determine the temperature distribution when heat losses at the ends were reduced merely by the action of the double plug without supplying any heating current to the coils in the end blocks. Two typical results at widely differing temperatures are shown in Fig. 12. In this (and also in Fig. 13) the full lines to the right and the dash lines to the left represent explorations with two different thermoelements. Perfect agreement in the region where both overlap is not to be expected; partly because of slight heterogeneity in the elements; partly because some points investigated with one are passed over with the other, and because moving a thermoelement into the furnace disturbs the gradient slightly, especially if not done very slowly. The dotted lines represent on the same scale the results obtained by Day and Sosman with the method of crowded windings, the roman numerals designating the furnaces, and the temperatures being those at the center. 


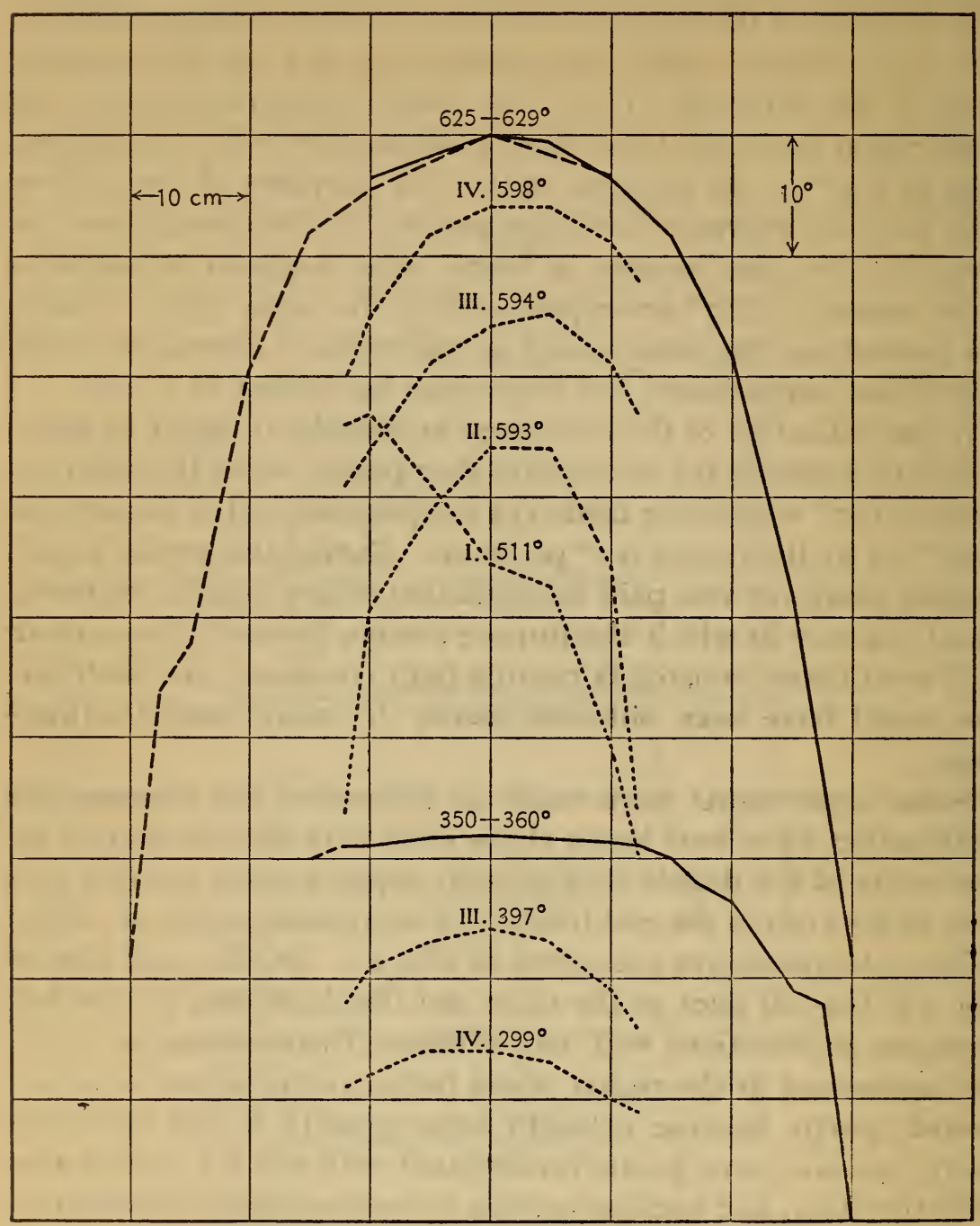

Fig. 12.-Distributions of temperature obtained by using the double plugs without supplying any heating current to the coils in the end blocks. The dotted lines represent the results of Day and Sosman at neighboring temperatures, who attempted to compensate for the losses by the method of crowded windings 


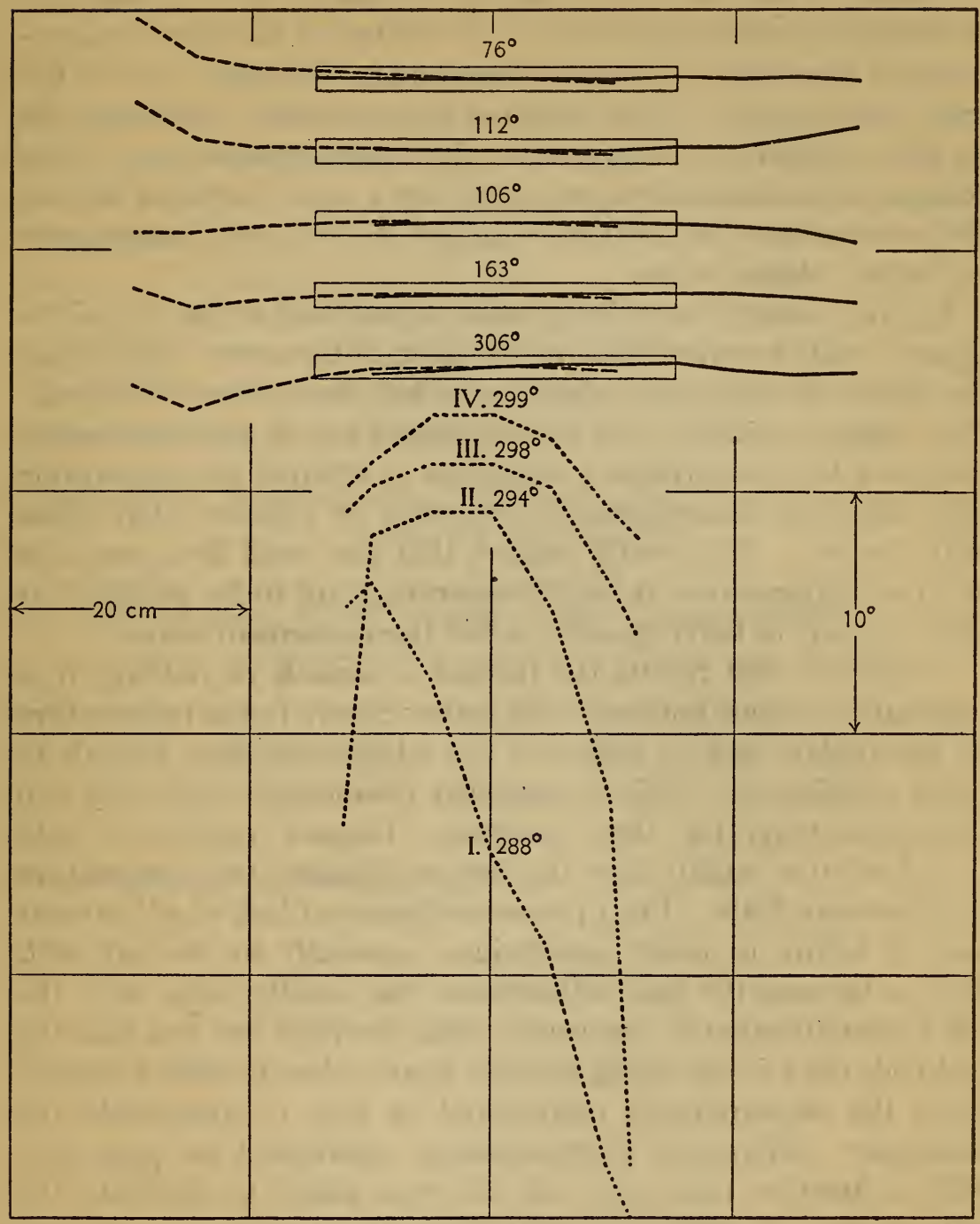

Fig. 13.-Distributions of temperature obtained after installing the flat end-heating coils. The length of each rectangle represents the $30 \mathrm{~cm}$ occupied by the specimen; the height represents one degree. The distributions are given for a total length of $60 \mathrm{~cm}$. The dotted lines below indicate on the same scale distributions obtained by Day and Sosman over $24 \mathrm{~cm}$ 
Fig. $\mathrm{r} 3$ is now presented to show the effect of heating the ends by means of the flat coils $\mathrm{H}$ and $\mathrm{H}^{\prime}, \mathrm{G}$ and $\mathrm{G}^{\prime}$ serving merely as transversely conducting blocks. At the top of the figure are represented the results of the first five consecutive runs after the flat coils were installed. The length of each rectangle represents the $30 \mathrm{~cm}$ occupied by the specimen; the height represents $I^{\circ}$. The temperature distributions are given for a total length of $60 \mathrm{~cm}$. For comparison distributions obtained by Day and Sosman over $24 \mathrm{~cm}$ are placed below.

In every temperature distribution represented at the top of the figure it will be noticed that to the right of the center the full line lies above the dash line, while to the left the reverse is the case. This same peculiarity was also exhibited by all the distribution curves of later experiments, regardless of whether the exploration with the right thermoelement preceded or followed that made with the left. This would suggest that the small divergences in the two explorations at each temperature are to be ascribed, at least in part, to heterogeneity in the thermoelement wires.

To get the best results the furnace is capable of yielding, it is necessary to adjust both end coils rather closely to the temperature at the middle and to maintain the adjustment long enough to reach equilibrium. This is somewhat troublesome with only two thermojunctions for three positions, because pushing a cold porcelain tube rapidly into the furnace disturbs the temperature distribution a little. Fig. 13 shows evidences of lack of adjustment and of failure to reach equilibrium, especially in the left half. This is because the final adjustment was usually made with the left thermojunction at the center, while the right one was near the end coil, the left end being allowed more or less to shift for itself. Since the measurements represented by Fig. I 3 were made, the stationary differential thermoelement mentioned on page 465 , with a junction near each end coil, was added to facilitate the adjustment. A sensitive detector indicating temperature changes close to the main heater would aid in maintaining constancy during the time the potentiometer is being used for the measurements proper. The results exhibited were obtained with a single galvanometer in the regular course of expansion determinations. 
That no unusual effort is required to obtain fair uniformity of temperature is shown by the table below, which represents 16 consecutive runs made while determining the expansivity of a bar of invar. Alongside the temperature observed at the center is recorded the correction that must be added to obtain the mean temperature throughout the $30 \mathrm{~cm}$ occupied by the bar. In many of the runs the heating currents required to maintain the desired temperature were estimated and switched on late in the afternoon. The furnace was then left to itself overnight. The temperature distribution found the following morning was explored and used. Reference to the table shows that in only one case (and that under known unfavorable conditions) did the mean temperature differ by more than $0.16^{\circ}$ from that at the center.

Temperature Distributions in Consecutive Trials of the Electric Furnace Shown in Figs. 4 and 5

\begin{tabular}{|c|c||c|c||c|c||c|c|}
\hline $\begin{array}{c}\text { Tempera- } \\
\text { ture }\end{array}$ & Correction & $\begin{array}{c}\text { Tempera- } \\
\text { ture }\end{array}$ & Correction & $\begin{array}{c}\text { Tempera- } \\
\text { ture }\end{array}$ & Correction & $\begin{array}{c}\text { Tempera- } \\
\text { ture }\end{array}$ & Correction \\
\hline$\cdot$ & 0 & 0 & 0 & 0 & 0 & - & - \\
390 & -0.16 & 242 & +0.13 & 233 & -0.10 & 445 & -0.25 \\
393 & -0.13 & 170 & -0.04 & 214 & -0.05 & 294 & -0.05 \\
278 & -0.03 & 188 & +0.04 & 344 & -0.05 & 262 & +0.03 \\
271 & +0.03 & 207 & -0.10 & 314 & -0.10 & 175 & +0.15 \\
\hline
\end{tabular}

WASHINGTON, February 3, 1914. 

$\longrightarrow$ 


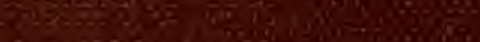

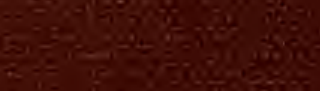

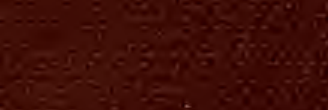

